\title{
HVMANITAS
}

\section{[Recensão a] Ferreira, José Ribeiro e Ferreira, Luísa de Nazaré (coord.) - As Sete Maravilhas do Mundo Antigo}
Autor(es):
Serrão, Vitor
Publicado por:
Faculdade de Letras da Universidade de Coimbra, Instituto de Estudos Clássicos
URL persistente:
URI:http://hdl.handle.net/10316.2/27963
DOI:
DOI:http://dx.doi.org/10.14195/2183-1718_61_19
Accessed :
26-Apr-2023 14:51:56

A navegação consulta e descarregamento dos títulos inseridos nas Bibliotecas Digitais UC Digitalis, UC Pombalina e UC Impactum, pressupõem a aceitação plena e sem reservas dos Termos e Condições de Uso destas Bibliotecas Digitais, disponíveis em https://digitalis.uc.pt/pt-pt/termos.

Conforme exposto nos referidos Termos e Condições de Uso, o descarregamento de títulos de acesso restrito requer uma licença válida de autorização devendo o utilizador aceder ao(s) documento(s) a partir de um endereço de IP da instituição detentora da supramencionada licença.

Ao utilizador é apenas permitido o descarregamento para uso pessoal, pelo que o emprego do(s) título(s) descarregado(s) para outro fim, designadamente comercial, carece de autorização do respetivo autor ou editor da obra.

Na medida em que todas as obras da UC Digitalis se encontram protegidas pelo Código do Direito de Autor e Direitos Conexos e demais legislação aplicável, toda a cópia, parcial ou total, deste documento, nos casos em que é legalmente admitida, deverá conter ou fazer-se acompanhar por este aviso.

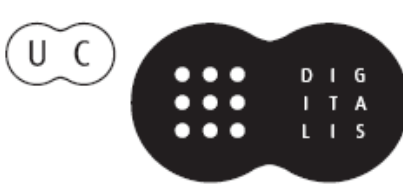


humanitas

\section{Vol. LXI}

IMPRENSA DA UNIVERSIDADE DE COIMBRA

COIMBRA UNIVERSITY PRESS 


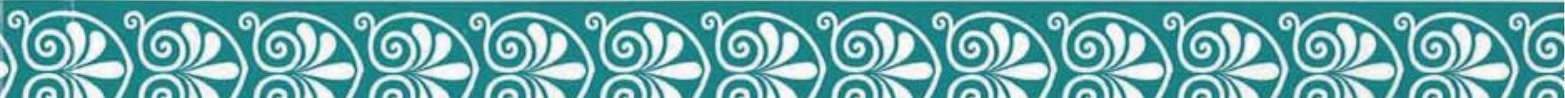

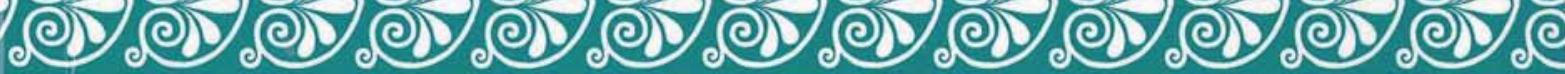

Vol. LXI 
De facto, lido o seu interessante trabalho, somos mais levados a pensar que a conversão de locais pagãos em cristãos teria ocorrido com menor sobressalto do que no Oriente: fosse porque eram ocupados locais anteriormente abandonados, fosse porque os ocupantes dos espaços eram os mesmos, e que, ao converterem-se ao novo culto, adaptavam o antigo espaço às antigas necessidades (um batistério num antigo templo pagão), fosse porque os edifícios públicos tivessem perdido a sua funcionalidade específica, por força de lei ou por mudança de hábitos (teatros, anfiteatros e termas), mas não o seu carácter colectivo e público.

\section{Paula Barata Dias (Universidade de Coimbra)}

Ferreira, José Ribeiro e Ferreira, Luísa de Nazaré (coord.), As Sete Maravilhas do Mundo Antigo. Fontes, Fantasias, Reconstituições, Lisboa, Edições 70, 2009, 248 pp. ISBN: 978-972-44-1566-6.

Seguindo os escritos de Fílon de Bizâncio e de Antípatro de Sídon (séc. III-II a.C.), passando pelos Laterculi Alexandrini ou os textos de Heródoto, Xenofonte, Teofrasto, Políbio, Calímaco, Vitrúvio, Diodoro Sículo, Estrabão, Plínio o Velho, passando por São Lucas, Gregório de Tours, Isidoro de Sevilha, Ciríaco de Ancona, Ângelo Poliziano, até às Pinaces (1572) de Adriaen de Jonghe, com o seu 'corpus' de gravuras maneiristas por Maerten van Heemskerck, é notório que os homens procuraram, desde a Antiguidade, destacar a primazia das notabilidades artísticas através de uma listagem de superiora, "as melhores obras entre as melhores". Engenho, talento, rigor tecnológico e científico, harmonia, fama, constituíram (e continuam a constituir) critérios de classificação desse verdadeiro "guia para os viajantes instruídos" de que falava Fílon de Bizâncio e incluía como mirabilia as Muralhas e o Jardim Suspenso de Babilónia, as Pirâmides de Mênfis, a escultura de Zeus por Fídias em Olímpia, o colosso de Hélios na ilha de Rodes, o Mausolo de Halicarnasso e o templo de Ártemis em Éfeso. O fascínio gerado por estas maravilhas do Mundo Antigo (do substantivo grego thauma, objecto admirável, e do verbo thaumazo, olhar com respeito e encanto) levou a que o seu elenco fosse várias vezes discutido e reformulado, até que (já com inclusão do Farol de Alexandria) a lista terá sido fixada por Adriaen de Jonghe na segunda metade do século XVI. 
É este tema tão apaixonante quanto actual que mereceu à equipa coordenada desde a Universidade de Coimbra por José Ribeiro Ferreira e Luísa de Nazaré Ferreira um estudo exemplar. A partir de uma reflexão conjunta que incluiu o escopro de especialistas como Luís Manuel de Araújo, Nuno Simões Rodrigues, Maria Helena da Rocha Pereira, Rui Morais, Delfim Ferreira Leão, Vasco Gil Mantas e Paula Barata Dias, pôde nascer um notável ensaio de âmbito pluridisciplinar, que as Edições 70 acabam de dar à estampa com cuidadoso grafismo, e que surge enriquecido ademais por uma exaustiva antologia de fontes gregas e latinas sobre as maravilhas do Mundo Antigo, de consulta doravante incontornável. Lamente-se, tão só, que tal antologia de fontes literárias não surja complementada por um elenco de fontes iconográficas sobre as sete maravilhas, sabendo-se como a arte europeia do Renascimento, do Maneirismo e do Barroco tanto privilegiou o simbolismo antigo desses temas, em pinturas, gravuras ou azulejos.

Segundo os autores deste belíssimo livro, que características conferem a um objecto o estatuto de obra-prima, de maravilha no seio do Património comum? Será o facto de se poder considerar perfeito, dos primeiros no género, de ser dotado de tal grau de qualidade e novidade que assume carácter 'unicum' no conjunto de produções da sua época e civilização? Luís Manuel de Araújo destaca, a respeito das pirâmides de Guiza - único testemunho remanescente dessas sete maravilhas eleitas pelos antigos -, o sublime conceito de maet, "palavra egípcia de amplo espectro humanista que significa verdade, justiça, equilíbrio, ordem, harmonia, solidariedade..." e parece reunir, juntamente com os predicados do rigor tecnológico e da fama intemporal, os requisitos qualificantes dessas apregoadas maravilhas. O princípio de identidade das 'obras-primas' desenvolveu-se com o Renascimento, em retoma dos códigos vitruvianos, através da literatura parangonal, dos livros de viagens e da crítica da arte, géneros que assumiram uma vertente com tónus laudatório para destacar as riquezas das regiões a partir dos monumentos, antiguidades, ruínas e obras de arte. Em Portugal, com a revalorização do conceito de Património da Humanidade, a noção de obra-prima consagra-se no Romantismo (através dos emblemáticos 'monumentos pátrios') em torno de casos como a Torre de Belém, a Batalha, Tomar, Jerónimos, Mafra, a Pena e outros exemplos de indiscutível valia. Em todas as civilizações foi acentuado, entre contornos de lenda e desvios de mitificação, a valência das 'obras-primas' domésticas, desde os monumentos da História a peças significativas do património móvel. Francisco 
de Holanda, por exemplo, colocava Nuno Gonçalves entre as 'águias' da Pintura e elogiou os Painéis de São Vicente da Sé de Lisboa como 'obra- prima'. Os textos dos sécs XVII-XVIII sobre Vasco Fernandes (c. 1475-1542), famoso pintor do Renascimento, destacam-no como "o grande Vasco" e põem ênfase na qualidade única (obra-prima) de quadros como o $\mathrm{S}$. Pedro da Sé de Viseu, considerado "obra-mestra" e "oitava maravilha do mundo". O fenómeno mitificador que rodeia "grandes artistas" e "obras-primas" assenta na superstição e no abuso de fontes contaminadas, mesmo quando abundam as bases gratulatórias de um reconhecimento que a investigação científica veio reconhecer como certa. Mal seria que os estudos artísticos se reconfortassem com este tipo de noção valorativa para, esquecidos os contextos, se desvalorizarem os "outros patrimónios" à luz de uma auto-menorização que deve ser sempre alvo de crítica.

O conceito de obra-prima coabita com a dimensão do mito e estratégias de constrangimento ideológico que a pesquisa da História, da Arte, da Arqueologia e da Filologia - como bem se explicita neste livro lançado pelas Edições 70 - permite dilucidar nos seus vastos contornos. De facto, o termo obra-prima continua a ser ambíguo: conceitos como 'masterpiece', 'capolavoro', 'chef-d'oeuvre', 'capo-d'opera', 'chefe de obra', 'chief excellence', 'obra-mestra' etc., utilizados no mundo técnico-profissional e no ensino das artes, atestam sobretudo a ideia de que se restringe a um âmbito artesanal, à competência de um mestre no seio do seu atelier. Só com o Renascimento, o termo designa as obras que, por razões de consenso na sociedade, seriam dignas de eterna admiração (cf. Walter Cahn, Masterpieces. Chapters on the History of an Idea, Princeton, 1979). Da obra-prima clássica para a obra-prima absoluta, a valoração evoluiu no sentido de aduzir a este estatuto problemático uma hierarquia de valores e 'evidências' que passou a necessitar de 'prova' concludente sobre o carácter 'unicum'. Pesem os contornos de imprecisão e mistificação histórica, a noção de obra-prima interessa à História porque ajuda a explicar as circunstâncias em que arte e público chegam ao encontro revelador das liturgias destinadas a conferir durabilidade (permanência) às suas escolhas de eleição, mesmo quando vitimadas pela iconoclastia e pela desmemória dos homens.

A validação de qualidade artística da 'obra-prima' vai exigir uma sanção pública dos seus méritos, à luz de uma série de critérios (designadamente o da autenticidade, ratificado pelas Convenções da UNESCO em Nara e Cracóvia) que a nós, historiadores, sobremaneira interessam pois 
explicam gostos, preferências e mitos das sociedades. Exemplo dado por Cahn é o Oratório de Margarida de Áustria na igreja de Brou (Ain), citado como 'obra-prima' por Jean Lemaire, cronista daquela princesa que chega a incluí-lo nas 'sete maravilhas do Mundo'. A duquesa Margarida de Áustria (n. 1480-1530) foi mulher do rei Carlos VIII, de Juan de Castilha e de Filiberto o Belo, e fundou em Brou uma capela funerária com complexo programa iconográfico em torno da Couronne margaritique, elogio da Virtude. O sentido humanístico definido por Lemaire, pelo engenheiro Jean Pérral e pelos artistas (Thibaut Landry, Michel Colombe) explica a qualidade da obra de Brou, que exigia nível de 'chef d'oeuvre'. O elogio das Dez Virtudes acentua o sentido do programa da capela, concebida como biografia imaginizada da duquesa, atestado das suas qualidades e feitos heróicos. De facto, o que torna uma obra de arte uma 'obra-prima'? Desde a mais remota Antiguidade, passando pela Idade Média até aos nossos dias (Sete Maravilhas de Portugal, Sete Maravilhas Portuguesas no Mundo, etc.), a expressão foi utilizada com função crítica raras vezes unívoca. De um sentido mais restrito, durante a Idade Média (no âmbito de uma estrutura gremial), torna-se termo de valorização suprema aplicado aos aspectos mais elevados do engenho e actividade criadora dos homens. Assim, quando uma obra se torna bem comum indiscutido, e nos prende, como encarnação superior da habilidade, do talento, do poder de expressão de uma época ou de um dado autor, denominamo-la 'obra-prima'.

Existiram sempre obras mais marcantes do que a maioria das contemporâneas, fosse pela novidade plástica, pelo programa narrativo, pelo significado ideológico, por um reconhecido poder de vanguardismo ou, enfim, pelo poder de síntese do que se julga fossem os 'grandes valores' de uma época histórica. As Maravilhas atestam um 'unicum' trans-contextual, com marca indelével de memorização, inesgotabilidade de impressão afectiva, código imagético aptas a enfrentar os tempos e manter incólume a sua contagiante magia. Porque há obras de arte que, efectivamente, olham para o futuro! Tal noção valorativa excepcional não pode sobrepor-se em nenhuma circunstância ao estudo integral das obras como efeito de uma leitura organizada em defesa de um olhar micro-artístico em globalidade, passível de (sem preconceitos preliminares) interpretar os fenómenos em cada contexto e época, à luz das suas especificidades. Como diz Didi-Huberman: "il y a toujours le choix entre dix manières de savoir, dix logiques d'agencement, et chaque catalogue particulier résulte d'une option implicite ou non, consciente ou non, idéologique en tout cas - à l'égard 
d'un type particulier de catégories classificatoires. (...) L'attribution et la datation elles-mêmes engagent toute une 'philosophie' - à savoir la manière de s'entendre sur ce que c'est une 'main', la paternité d'une 'invention', la regularité ou maturité d'un 'style', et tant d'autres catégories encore qui ont leur propre histoire, ont été inventées, n'ont pas toujours existé. C'est bien l'ordre du discours qui mène, en histoire de l'art, tout le jeu de la pratique" (Georges Didi-Huberman, Devant l'image. Questions posées aux fins d'une histoire de l'art, Paris, éd. Minuit, 1990).

Quando uma obra nos toca a sensibilidade como a mais alta encarnação do talento e do engenho, a História tendeu a denominá-la como 'obra -prima' de um dado artista ou uma dada época. Ilusão de superlativos, em que a História da Civilização dos homens encontra referências e códigos memoriais já de si cómodos, a obra-prima aspira a um ideal universal consequente, a expressão do consenso histórico, político e mesmo metafísico. Ao longo dos tempos, a obra-prima como tal eleita proclamou valores soberanos e abriu expectativas de revalorização e significação. É possível fazer-se História de Arte sem o recurso às chamadas 'obra -primas'? Ou só com o recurso às ditas 'obra -primas'? A questão tem, para os defensores de uma Micro-História da Arte, a maior pertinência: a História tradicional socorreu-se sempre de tais 'lugares de consenso' para fazer valer metodologias redutoras e formalistas, pelo que é preciso estudar o que encerra o conceito e saber descobrir-lhe as fragilidades. Só com o estudo da globalidade que se exprime em qualquer obra se atinge o conhecimento de um processo em cadeia de que todas e cada uma são parte activa. A noção de 'obra-prima' - pensada como referencial absoluto e universal - torna-se redutora e deve ser vista apenas como um dos processos de classificação que a Humanidade assumiu face ao Património perecível, consciente da necessidade de o preservar.

A obra agora lançada constitui-se como livro exemplar, que supera uma lacuna antiga na bibliografia portuguesa e também estrangeira, num temário que vem merecendo nos últimos anos, fruto das campanhas arqueológicas, novos esclarecimentos. Entre nós, registo tão-só um contributo de Maria Adelina Amorim (Condicionantes Culturais da Literatura de Viagens. Estudos e Bibliografias, ed. Cosmos) ao abordar os mirabilia à luz das peregrinações aos Santuários da Humanidade, os itinerários das 'rotas de ouro' e especiarias com seus espantos e prodígios, as novas rotas abertas em direcção ao Oriente que "começaram a marcar lugar nas obras mais apreciadas pelo público e vão constituir um 'corpus' próprio, que, à 
semelhança das tradicionais enciclopédias do Medievo, eram identificadas como mirabilia". Não era relevante se as viagens eram reais, se o autor era protagonista ou contador de relatos, mas o falar de coisas estranhas, "águas de vida", raças monstruosas, fontes da eterna juventude, o reino mítico de Preste João, as nascentes dos rios que conduziam ao Paraíso Terreal, "a maravilha das maravilhas". A par dessas histórias, corriam relatos sobre as sete maravilhas do mundo segundo a tradição de Antípatro. Aliando um sentido prodigioso ao mito e à tradição, os mirabilia marcam um estilo narrativo de glorificação que se perpetua... Recordo Umberto Eco e o seu Baudolino (trad. ed. Difel, 2002) e o conselho de Otão de Frisinga ao protagonista: "Ouvi-te inventar muitas histórias em que o Imperador acreditava. Portanto, se não tiveres outras notícias deste reino, inventa-as. Atenção, não te peço para testemunhares o que consideras falso, que seria pecado, mas que testemunhes falsamente o que julgares verdadeiro - o que é acção virtuosa por suprir a falta de provas sobre alguma coisa que certamente existiu ou que aconteceu".

O conceito de Maravilha tão bem historiado neste livro das Edições 70 está ligado também, naturalmente, ao conceito de imortalidade no seu sentido metafórico que remete para valores simbólicos de arquétipo. "Só uma externa simplicidade aliada a uma profunda carga metafórica farão que uma obra de arte perdure na memória, isto é, no tempo", escreveu Pedro Cabrita Reis. Por tudo isso se defendeu e defende da parte de quem trabalha no campo do Património, ou de quem simplesmente o frui, um olhar integral para as obras de arte, sem estigmas de redução e/ou de mitificação, não como meros testemunhos históricos já de si datados, ou como 'obras-primas' deificadas e inacessíveis, mas como interlocutores vivos. Haverá que olhar os monumentos e obras de arte - estudadas, e como tal "explicadas", no seu contexto temporal e geográfico, estilístico e ideológico - como instrumentos eloquentes que nos revelam desejos, fascínios, anseios e memórias, sonhos, protestos, indagações e energias vitais, num sentido de criação que, com maior ou menor sucesso, procurou rasgar caminhos da comunicabilidade social. 